\title{
Alcohol and hepatocyte-Kupffer cell interaction (Review)
}

\author{
MICHAEL AJAKAIYE, ASHA JACOB, RONGQIAN WU, \\ JEFFREY M. NICASTRO, GENE F. COPPA and PING WANG
}

\begin{abstract}
Department of Surgery, North Shore University Hospital-Long Island Jewish Medical Center, and Laboratory of Surgical Research, The Feinstein Institute for Medical Research, Manhasset, NY, USA
\end{abstract}

Received December 15, 2010; Accepted March 23, 2011

DOI: $10.3892 / \mathrm{mmr} .2011 .471$

\begin{abstract}
Alcoholic liver disease accounts for 12,000 deaths per year in the United States and is the second leading indication for liver transplantation. It covers a spectrum of disease conditions ranging from steatosis and cirrhosis to hepatic malignancies. Epidemiological data clearly show a strong correlation between alcohol consumption and liver diseases. A large body of evidence has accumulated over the years in determining the molecular mediators of alcohol-induced liver injury. In this review, we provide an overview of such mediators, which include alcohol metabolites and reactive oxygen/ nitrogen species, endotoxin via bacterial translocation from the gut and TNF- $\alpha$, and highlight the role of the sympathetic nervous stimuli, norepinephrine and the $\alpha_{2 \mathrm{~A}}$-adrenergic receptors in contributing to the deleterious effect observed in alcohol-induced hepatic dysfunction.
\end{abstract}

\section{Contents}

1. Introduction

2. Sympathetic nervous system and alcoholic liver disease

3. Direct effect of ethanol on Kupffer cell activation by norepinephrine

4. Alcohol metabolites and ROS-associated alcohol-induced hepatic injury

5. Gut permeability and bacterial translocation in alcoholinduced hepatic damage

6. TNF- $\alpha$ and alcohol-induced hepatic damage

7. Hepatic stellate cell activation in alcohol-induced hepatic damage

8. Summary and conclusions

Correspondence to: Professor Ping Wang, Department of Surgery, North Shore University Hospital-Long Island Jewish Medical Center and The Feinstein Institute for Medical Research, 350 Community Drive, Manhasset, NY 11030, USA

E-mail: pwang@nshs.edu

Key words: norepinephrine, adrenergic receptors, Kupffer cells, reactive oxygen species, alcohol metabolites, bacterial translocation

\section{Introduction}

... if the surfeit of delicacies, or the hereditary wine of my country dared to disturb my health or the equilibrium of my poetry, from you, dark monarch, giver of syrups and of poisons, regulator of salts, from you I hope for justice: I love life: Do not betray me! Work on!

-Pablo Neruda, Oda al Higado (1)

Alcoholic liver disease (ALD) affects $1 \%$ of the North American population and accounted for over 12,000 deaths in 2001. It is the second most frequent indication for a liver transplant in the United States, accounting for $18 \%$ of all patients awaiting liver transplants (2-4). A recent study from Europe showed a $2.8 \%$ prevalence of advanced hepatic fibrosis in the general population, with alcohol consumption, singly or in combination with hepatitis $\mathrm{C}$ infection, being the predominant risk factor in $75 \%$ of those affected (5). ALD covers a spectrum of increasing hepatic dysfunction, ranging from steatosis to liver failure and malignant hepatic disease. The most prevalent types of ALD are fatty liver, alcoholic hepatitis and cirrhosis $(6,7)$. As a major synthetic and metabolic organ, the liver plays an essential role in the body. It is a remarkably resilient organ and its parenchymal cells are capable of extraordinary regeneration.

Hepatic injury is primarily caused by infections and toxins, including alcohol, which contributes substantially to the burden of liver disease worldwide $(4,8)$. Liver injury resulting from alcohol use is mediated through several processes, including the generation of harmful metabolites and oxygen species in the local milieu, alteration of intestinal permeability and increases in bacterial toxins and changes in the levels of endogenous mediators $(9,10)$. The surest way of preventing ALD would be complete abstinence. Indeed, epidemiological data show a decrease in chronic liver disease by the end of the Prohibition in the US in 1914 (11). Alcohol, however, has also beneficial effects, and moderate alcohol consumption has been shown to improve digestion and cholesterol profile, and to lower the risk of ischemic heart disease $(12,13)$. Epidemiological data has shown a clear correlation between excessive and prolonged alcohol consumption and liver disease $(6,7)$. The molecular mechanisms underlying these interactions are still being elucidated.

The molecular mediators of alcohol-induced hepatic dysfunction have been elucidated over the years. It is widely 
thought that the autonomic nervous system is involved in alcohol-induced hepatic damage, and that the level of plasma norepinephrine (NE) is an independent prognostic factor in cirrhosis $(14,15)$. Our recent study suggested that NE-induced inflammatory response is a potential cause of alcohol-induced hepatic dysfunction. In addition, a large body of literature indicates the role of alcohol metabolites, reactive oxygen/ nitrogen species (RNS/ROS), bacterial translocation from the gut, TNF- $\alpha$ and hepatic stellate cell (HSC) activation as the combined cause of alcohol-induced hepatic damage. Therefore, a consensus has been emerging concerning the general pathway culminating in severe ALD involving a complex orchestration between Kupffer cells (KCs), HSC and hepatocytes $(7,9,16)$. This study reviews these concepts and highlights the key role played by the noradrenergic stimuli NE and its receptor in the causation of alcohol-derived injury in the liver.

\section{Sympathetic nervous system and alcoholic liver disease}

The autonomic nervous system influences many functions mediated by the neurotransmitter released and its interaction with the receptors. The primary responses of the autonomic nervous system are mediated via the cholinergic and adrenergic pathways. The adrenergic nervous system has NE as the major neurotransmitter in axon terminals of postganglionic fibers. The direct measure of sympathetic nervous activity is to measure the plasma concentration of NE. Norepinephrine from the synaptic cleft enters into the plasma, where its concentration reflects the activity of the sympathetic nervous system. A close association exists between plasma NE levels in venous blood in the forearm and sympathetic nervous activity in muscles during exercise, mental stress, hypoglycemia and in patients with liver disease $(17,18)$. A large body of evidence has accumulated over the past several decades that confirms the importance of sympathetic nervous activity in cardiovascular and homeostatic alterations, and in the metabolic syndrome present in advanced liver disease $(19,20)$. In addition, excessive consumption of alcohol may induce transient changes in the sympathetic nervous system. Autonomic dysfunction has been implicated in alcoholics. Even though there is increasing evidence of parasympathetic dysfunction, sympathetic defects may also be present in alcoholics (21). There has been increasing attention given to the potential role of the adrenergic system in ethanol consumption. Significantly elevated NE levels in active drinkers compared to 3-month abstinent alcoholics and non-drinking controls have been reported. In addition, NE concentrations have been shown to decline during the early withdrawal phase from days 1 to 14 of abstinence $(22,23)$.

High levels of catecholamines in the portal venous plasma of patients with cirrhosis were first reported by Shaldon et al (24). Subsequently, at the beginning of the 1980s, studies with isotope derivatives and high-pressure liquid chromatography showed increased circulating levels of NE and epinephrine in patients with cirrhosis and portal hypertension (25-28). In fact, a positive relation exists between circulating NE and epinephrine and the progession of the disease, and thus the level of plasma NE became an independent prognostic factor of cirrhosis $(14,15)$. This increased circulating NE in cirrhotic patients is caused by the sympathetic nervous activity of a number of organs, such as the liver, the prehepatic splanchnic areas, the heart and the kidney.

Increased levels of NE have been reported in both humans and in animal studies following alcohol consumption. Ireland et al reported elevated blood pressure with increased epinephrine levels and a later rise in NE in young human males following acute ethanol intake (29). Kovasc et al showed elevated plasma epinephrine and NE levels in mice following intraperitoneal injection of $1.75 \mathrm{~g} / \mathrm{kg}$ ethanol or ingestion of $5 \%$ ethanol in drinking water for $24 \mathrm{~h}$ (30). Using dopamine $\beta$ hydroxylase (DBH) knockout mice, a mouse strain that has the DBH gene deleted and thus no NE in the brain, adrenal glands or circulation (31), Weinshenker et al showed decreased preference for and consumption of ethanol, and increased ethanol-induced hypothermia and sedation in these animals, concluding that $\mathrm{NE}$ is a critical component of the response to ethanol (32). It has been postulated that under stressful conditions, $30 \%$ or more of plasma NE originates in the adrenal medulla $(33,34)$. Patterson-Buckendahl et al demonstrated that adrenomedullary gene expression from enzymes of the catecholamine synthetic pathway, tyrosine hydroxylase (TH), DBH and phenylethanolamine-N-methyl transferase (PNMT) was increased in rats after 7 weeks of consumption of $6 \%$ wt/vol ethanol in drinking water (35). In a similar study of a 1-week administration of a liquid diet containing 5\% wt/ vol ethanol in rats, ethanol potentiated a normal increase in the immobilization-induced increase in adrenomedullary TH, DBH and PNMT mRNA expression (36). These studies clearly demonstrated that NE levels are elevated in the plasma following chronic consumption of alcohol, and this increase is in part due to the up-regulation of the various mediators of the catecholamine synthesis pathway.

\section{Direct effect of ethanol on Kupffer cell activation by norepinephrine}

KCs are the resident macrophages of the liver. They ensure maximal liver function by removing bacteria and phagocytosing foreign materials. The importance of $\mathrm{KCs}$ in causing alcohol-induced injury in the liver was illustrated by Adachi et al (37). They demonstrated that twice weekly treatment of male rats with gadolinium chloride $(\mathrm{GdCl} 3)$, a selective Kupffer cell toxicant, to inactivate KCs, prevented injury in a rat model of ethanol-induced injury (37). KCs are quiescent in the absence of stimulatory agents. When activated, $\mathrm{KCs}$ release several inflammatory cytokines. These include TNF- $\alpha$, IL-1, IL-6 and TGF- $\beta$. Clinical studies have shown an increased production of TNF- $\alpha$ by circulating monocytes in patients with ALD. This has been corroborated by animal studies in chronically alcohol-fed animals $(38,39)$. KCs also produce significant amounts of ROS and other inflammatory mediators when activated. Direct production of ROS by $\mathrm{KCs}$ is catalyzed by NADPH oxidase. Cytokines secreted by $\mathrm{KCs}$, most significantly TNF- $\alpha$, contribute to increased ROS production. In addition, Kupffer cell facilitation of neutrophil infiltration contributes to ongoing oxidative stress through the generation of ROS via the myeloperoxidase pathway.

$\mathrm{NE}$ acts in the liver to activate KCs. Using a cecal ligation and puncture (CLP) model of rodent polymicrobial sepsis, we previously demonstrated that the up-regulation of 
pro-inflammatory cytokines, such as TNF- $\alpha$, is caused by the increased release of NE from the gut during sepsis. This is evidenced by our studies (40) and others (41), which show that peripheral sympathetic activity increases during sepsis, resulting in the elevation of plasma levels of NE. Intraportal infusion of $\mathrm{NE}$ in vivo increased $\mathrm{TNF}-\alpha$ release and was inhibited by co-infusion with yohimbine, a non-specific antagonist of the $\alpha_{2}$-adrenergic receptor. Cellular levels of TNF- $\alpha$ in KCs were also significantly increased following intraportal $\mathrm{NE}$ infusion, and were inhibited by co-infusion with yohimbine (42). KCs isolated from rats during early sepsis exhibited a marked increase in the mRNA expression of the $\alpha_{2 \mathrm{~A}}$-adrenergic receptor subtype $(43,44)$. Furthermore, Zhou et al showed increased TH gene expression and protein levels in the intestine of septic rats, suggesting that the increased NE levels are due to an increase in NE biosynthesis from the gut (45). These studies in sepsis showed that NE released from the gut during sepsis enters the liver through the portal vein and binds to $\alpha_{2 \mathrm{~A}}$-adrenergic receptors on $\mathrm{KCs}$, facilitating the increased production of TNF- $\alpha$.

Although previous studies have reported that the adrenal medulla is the major contributor for ethanol-induced $\mathrm{NE}$ release, it is possible that the release of NE by the intestine as evidenced in sepsis also contributes to alcoholic liver injury via the gut-liver axis. Nevertheless, in vitro experiments from our laboratory with rat KCs treated with ethanol for 7 days, i.e., chronic condition, showed a $120 \%$ increase in $\alpha_{2 A}$-adrenergic receptor mRNA expression. This was reflected by a $98 \%$ increase in TNF- $\alpha$ mRNA expression in the cultured KCs, and is supported by the attenuation of the Kupffer cell response to the portal vein infusion of NE by the specific $\alpha_{2 \mathrm{~A}}$-adrenergic receptor inhibitor BRL44408 maleate (43). Paradoxically, NE also acts on $\mathrm{KCs}$ via the $\beta$-adrenergic receptor to depress their phagocytic and immune functions (46-48). Ethanol exposure leads to increased circulating $\mathrm{NE}$ and the activation of $\mathrm{KC}$ $\beta$-receptors. This results in the depression of $\mathrm{KC}$ immune function via the activation of adenylate cyclase. This particularly affects the phagocytosis and cytocidal actions of these macrophages $(48,49)$. Recently, Parlesak et al showed that ethanol significantly depressed the amount of ROS released by LPS-stimulated monocytes (50).

Ethanol potentiates the release of pro-inflammatory cytokines by up-regulating $\mathrm{KC} \alpha_{2 \mathrm{~A}}$-adrenergic receptors, and their activation leads to the increased release of pro-inflammatory cytokines, in particular TNF- $\alpha$. Thus, the interaction of ethanol and NE with KCs leads to several deleterious effects typified by the clinical effects observed in the chronic alcoholic. Ethanol potentiates cytokine-mediated injury by priming $\mathrm{KCs}$ to respond to $\mathrm{NE}$ by producing $\mathrm{TNF}-\alpha$, which mediates a variety of hepatotoxic effects by direct toxicity and the activation of HSCs. Ethanol also promotes LPS-associated hepatic damage by depressing the immune function of KCs. Ethanol consumption has been linked to endotoxemia and increased susceptibility to infections from microorganisms that would ordinarily have been cleared from the circulation by $\mathrm{KCs}$. In addition, this suppression of KC cytotoxicity inhibits its tumoricidal activity and is implicated in the multifactorial development of hepatic malignancies $(51,52)$.

KCs express $\alpha$ - and $\beta$-adrenergic receptors, however, and the relative activation of these receptor subtypes determines the differential response of KCs to NE. However, a likely effect of chronic alcohol consumption is the up-regulation of $\alpha_{2 \mathrm{~A}}$-adrenergic receptors in KCs. This probably explains the contrasting effects of NE increase in the liver with moderate versus chronic or excessive alcohol intake. An intriguing new development has been the demonstration of endogenous $\mathrm{NE}$ secretion by macrophages and other immune and inflammatory cells $(30,53,54)$. This requires further study, particularly as it raises the possibility of a self-perpetuating cycle of autocrine stimulation of KCs by endogenously-derived NE in the causation of hepatic injury.

\section{Alcohol metabolites and ROS-associated alcohol- induced hepatic injury}

Alcohol is primarily metabolized in the liver through two pathways: the alcohol dehydrogenase (ADH) pathway and the microsomal ethanol-oxidizing system (MEOS). After moderate intake, most of the alcohol is broken down by $\mathrm{ADH}$, which converts ethanol to acetaldehyde with the reduction of nicotinamide adenine dinucleotide (NAD) to reduced NAD (NADH). Subsequently, the acetaldehyde is converted to acetate by a second enzyme, aldehyde dehydrogenase. The MEOS comes to play particularly after higher alcohol consumption. The main component of the MEOS is the enzyme cytochrome P450, which also converts alcohol to acetaldehyde. Acetaldehyde has been shown to cause the injury and death of hepatocytes. It forms adducts with proteins and DNA and therefore impairs microtubules, decreases protein secretion and causes protein retention and ballooning of the hepatocyte. Acetaldehyde exerts toxicity also with regard to other key cellular functions, particularly in the mitochondria, and it may promote the peroxidation of the cellular membranes (55-57).

Alcohol acting through its metabolites produces oxidative stress by enhancing the production of ROS/RNS and by inhibiting the protective antioxidant enzyme systems. Reactive species, primarily the superoxide radical $\mathrm{O}_{2}{ }^{\bullet}$, the peroxide $\left(\mathrm{O}_{2}=\right)$-containing hydrogen peroxide radical $\left(\mathrm{H}_{2} \mathrm{O}_{2}\right)$ and the hydroxyl radical $(\bullet \mathrm{OH})$, cause hepatic damage by interacting with constituent cellular molecules, including lipids, in the cell membrane, cellular proteins and DNA. Lipid peroxidation of the bi-lipid plasma membrane of the cells generates more radicals and results in extensive cellular damage (10). Cysteine, methionine and histidine are amino acids that are particularly sensitive to attack and oxidation by the hydroxyl radical (58). This results in the inactivation of crucial enzymes, and conformational changes in protein structure. The results of these insults are permanent cell damage or death. Mutations that occur, when persistent, may lead to cell transformation and eventual malignancy.

\section{Gut permeability and bacterial translocation in alcohol- induced hepatic damage}

The permeability of the gut mucosa is increased following alcohol intake. This leads to a rise in the translocation of endotoxin from the gut into the circulation. Alcohol also alters the gut microflora, in particular when consumed chronically, with a shift towards increased gram-negative bacteria. This, 
too, increases circulating bacterial endotoxin. Experiments in animals have revealed that the liver quickly removes intravenously administered endotoxin from the bloodstream $(59,60)$. This would be the case in the portal circulation with relatively higher gut-derived endotoxin due to the first pass effect (61). Hepatic uptake and detoxification is essential for preventing systemic reactions to blood-borne LPS, a gram-negative bacterial endotoxin. The endotoxins released by these bacteria activate KCs by binding to TLR4 and its co-receptors, CD14 and MD-2 (62), leading to the release of inflammatory cytokines, in particular TNF- $\alpha$.

\section{TNF- $\alpha$ and alcohol-induced hepatic damage}

Clinical and animal studies have revealed TNF- $\alpha$ to be a key mediator of the hepatic damage that occurs in alcoholinduced liver injury $(63,64)$. Its adverse effects on cells range from mitochondrial damage to oncotic necrosis and apoptosis. Activated KCs release TNF- $\alpha$ through a series of molecular steps involving sequential activation of transcription factor $N F-\kappa B$ via the TIR domain-containing adaptor myeloid differentiation factor 88 (MyD88) and the phosphorylation of transcription factor inhibitor I $\mathrm{B}$ by IKK (I $\kappa \mathrm{B}$ kinase). The disinhibition of transcription factor $N F-\kappa B$ by $\mathrm{I} \kappa \mathrm{B}$ leads to the nuclear translocation of $\mathrm{NF}-\kappa \mathrm{B}$. NF- $\kappa \mathrm{B}$ initiates cytokine gene transcription leading to the up-regulation and release of TNF- $\alpha$ and other pro-inflammatory cytokines $(62,65,66)$. TNF- $\alpha$ amplifies and prolongs the inflammatory response by activating cells to release pro-inflammatory cytokines, such as IL-1 and high mobility group B1 (HMGB1), as well as mediators, such as eicosanoids, nitric oxide and ROS. These promote further inflammation and tissue injury (67). Studies have shown that gut-derived NE itself induces the release of TNF- $\alpha$ from KCs and leads to hepatic dysfunction $(43,44)$. However, as its action depends on its interplay with other cytokines and the general hepatic milieu $(63,68), \mathrm{TNF}-\alpha$ does have physiologically beneficial effects, thus straightforward antagonism would not necessarily be an effective intervention.

\section{Hepatic stellate cell activation in alcohol-induced hepatic damage}

The interaction of $\mathrm{KCs}$ with other component cells of the liver, most notably HSCs, is another mechanism of alcoholicinduced hepatic damage. Physiologically, HSCs act as fat storage cells in the liver and are a reservoir for lipid soluble vitamins. Hepatic stellate cells, which are pericytes, are nominally differentiated cells capable of transforming to different lineages following liver damage. However, during chronic inflammation following continuous cytokine stimulation, these cells become activated and are transformed to myofibroblasts responsible for the hepatic scarring that culminates in liver cirrhosis. Activated HSCs proliferate and undergo phenotypic transdifferentiation to become myofibroblasts. This is believed to be the central pathogenetic event in the development of fibrosis. Cytokines secreted by KCs, particularly TGF- $\beta$ and TNF- $\alpha$, are central to this activation. HSC transformation to myofibroblasts can be summarized as a three step cascade: a pre-inflammatory phase that initiates HSC activation by discharge of mitogenic cytokines (TGF- $\alpha$,
IGF-1) from damaged and apoptotic hepatocytes, followed by the inflammatory phase, based on cytokines (platelet-derived growth factor, TGF- $\beta$, TNF- $\alpha$ ) from activated KCs. The consecutive post-inflammatory phase is characterized by the secretion of fibrogenic cytokines from myofibroblasts and interacting matrix components potentially contributing to a perpetuation of the fibrogenic process even after cessation of the primary event $(69,70)$.

\section{Summary and conclusions}

Alcohol abuse plays a significant role in the causation of liver disease worldwide. Hepatic damage resulting from alcohol consumption is manifested in a spectrum of clinical and histopathological changes. KCs play a central role in the initiation and propagation of hepatic dysfunction through their production of several intermediaries. Ethanol increases NE release and potentiates NE-mediated dysfunction by up-regulating the $\alpha_{2 \mathrm{~A}}$-adrenergic receptors, thereby promoting the release of proinflammatory cytokines by KCs. Ethanol also depresses $\mathrm{KC}$ phagocytosis and the clearance of endobacteria, and in association with its effect on increasing gut permeability, potentiates endotoxin-Kupffer cell-mediated damage. This, in addition to the production of ROS and the activation of HSCs by KCs, highlights its dynamic role in the pathogenesis of alcoholic liver disease. The modulation of the Kupffer cell response to ethanol presents an exciting opportunity to attenuate the deleterious response of the liver to ethanol consumption and reduce the enormous morbidity associated with it.

\section{Acknowledgements}

This study was supported by the National Institutes of Health grants R01 GM053008 and R01 GM057468 (P.W.).

\section{References}

1. Neruda P: Oda al Higado. In: Alcohol Liver Pathology. Khana JM, Israel Y and Kalant H (eds), 1975.

2. CDC/MMWR: Alcohol-attributable deaths and years of potential life cost - United States, 2001. MMWR Morb Mortal Wkly Rep 53: 866-870, 2004.

3. Anantharaju A and van Thiel DH: Liver transplantation for alcoholic liver disease. Alcohol Res Health 27: 257-268, 2003.

4. Tan HH, Virmani S and Martin P: Controversies in the management of alcoholic liver disease. Mt Sinai J Med 76: 484-498, 2009.

5. Poynard T, Lebray P, Ingiliz P, et al: Prevalence of liver fibrosis and risk factors in a general population using non-invasive biomarkers (FibroTest). BMC Gastroenterol 10: 40, 2010.

6. Mann RE, Smart RG and Govoni R: The epidemiology of alcoholic liver disease. Alcohol Res Health 27: 209-219, 2003.

7. Menon KV, Gores GJ and Shah VH: Pathogenesis, diagnosis, and treatment of alcoholic liver disease. Mayo Clin Proc 76: 1021-1029, 2001.

8. McCartney EM and Beard MR: Impact of alcohol on hepatitis $\mathrm{C}$ virus replication and interferon signaling. World $\mathrm{J}$ Gastroenterol 16: 1337-1343, 2010

9. Miranda-Mendez A,Lugo-Baruqui A and Armendariz-Borunda J: Molecular basis and current treatment for alcoholic liver disease. Int J Environ Res Public Health 7: 1872-1888, 2010.

10. Wu D and Cederbaum AI: Alcohol, oxidative stress, and free radical damage. Alcohol Res Health 27: 277-284, 2003.

11. Herd D: Ideology, history and changing models of liver cirrhosis epidemiology. Br J Addict 87: 1113-1126, 1992.

12. Lippi G, Franchini M, Favaloro EJ and Targher G: Moderate red wine consumption and cardiovascular disease risk: beyond the 'French paradox'. Semin Thromb Hemost 36: 59-70, 2010. 
13. Rehm J, Gmel G, Sempos CT and Trevisan M: Alcohol-related morbidity and mortality. Alcohol Res Health 27: 39-51, 2003.

14. Tage-Jensen U, Henriksen JH, Christensen E, Widding A Ring-Larsen $\mathrm{H}$ and Christensen NJ: Plasma catecholamine level and portal venous pressure as guides to prognosis in patients with cirrhosis. J Hepatol 6: 350-358, 1988.

15. Gines A, Escorsell A, Gines P, et al: Incidence, predictive factors, and prognosis of the hepatorenal syndrome in cirrhosis with ascites. Gastroenterology 105: 229-236, 1993.

16. Eagon PK: Alcoholic liver injury: influence of gender and hormones. World J Gastroenterol 16: 1377-1384, 2010.

17. Wallin BG, Sundlof G, Eriksson BM, Dominiak P, Grobecker H and Lindblad LE: Plasma noradrenaline correlates to sympathetic muscle nerve activity in normotensive man. Acta Physiol Scand 111: 69-73, 1981 .

18. Floras JS, Legault L, Morali GA, Hara K and Blendis LM: Increased sympathetic outflow in cirrhosis and ascites: direct evidence from intraneural recordings. Ann Intern Med 114 373-380, 1991

19. Henriksen JH and Ring-Larsen H: Hepatorenal disorders: role of the sympathetic nervous system. Semin Liver Dis 14: 35-43, 1994.

20. Henriksen JH, Ring-Larsen H and Christensen NJ: Aspects of sympathetic nervous system regulation in patients with cirrhosis: a 10-year experience. Clin Physiol 11: 293-306, 1991.

21. Henriksen JH, Moller S, Ring-Larsen H and Christensen NJ: The sympathetic nervous system in liver disease. J Hepatol 29 : 328-341, 1998.

22. Patkar AA, Gopalakrishnan R, Naik PC, Murray HW Vergare MJ and Marsden CA: Changes in plasma noradrenaline and serotonin levels and craving during alcohol withdrawal. Alcohol Alcohol 38: 224-231, 2003.

23. Patkar AA, Marsden CA, Naik PC, et al: Differences in peripheral noradrenergic function among actively drinking and abstinent alcohol-dependent individuals. Am J Addict 13: 225-235, 2004

24. Shaldon C, Peacock JH, Walker RM, Palmer DB and Badrick FE: The portal venous content of adrenaline and noradrenaline in portal hypertension. Lancet 1: 957-961, 1961.

25. Henriksen JH, Christensen NJ and Ring-Larsen $\mathrm{H}$ : Noradrenaline and adrenaline concentrations in various vascular beds in patients with cirrhosis. Relation to haemodynamics. Clin Physiol 1: 293-304, 1981.

26. Bichet DG, van Putten VJ and Schrier RW: Potential role of increased sympathetic activity in impaired sodium and water excretion in cirrhosis. N Engl J Med 307: 1552-1557, 1982.

27. Arroyo V, Planas R, Gaya J, et al: Sympathetic nervous activity, renin-angiotensin system and renal excretion of prostaglandin E2 in cirrhosis. Relationship to functional renal failure and sodium and water excretion. Eur J Clin Invest 13: 271-278, 1983.

28. Nicholls KM, Shapiro MD, van Putten VJ, et al: Elevated plasma norepinephrine concentrations in decompensated cirrhosis. Association with increased secretion rates, normal clearance rates, and suppressibility by central blood volume expansion. Circ Res 56: 457-461, 1985.

29. Ireland MA, Vandongen R, Davidson L, Beilin LJ and Rouse IL: Acute effects of moderate alcohol consumption on blood pressure and plasma catecholamines. Clin Sci 66: 643-648, 1984.

30. Kovacs GL, Soroncz M and Tegyei I: Plasma catecholamines in ethanol tolerance and withdrawal in mice. Eur J Pharmacol 448 : 151-156, 2002.

31. Thomas SA, Matsumoto AM and Palmiter RD: Noradrenaline is essential for mouse fetal development. Nature 374: 643-646, 1995.

32. Weinshenker D, Rust NC, Miller NS and Palmiter RD: Ethanolassociated behaviors of mice lacking norepinephrine. J Neurosci 20: 3157-3164, 2000

33. Kvetnansky R, Weise VK, Thoa NB and Kopin IJ: Effects of chronic guanethidine treatment and adrenal medullectomy on plasma levels of catecholamines and corticosterone in forcibly immobilized rats. J Pharmacol Exp Ther 209: 287-291, 1979.

34. McCarty R and Kopin IJ: Stress-induced alterations in plasma catecholamines and behavior of rats: effects of chlorisondamine and bretylium. Behav Neural Biol 27: 249-265, 1979.

35. Patterson-Buckendahl P, Blakley G, Kubovcakova L, Krizanova O, Pohorecky LA and Kvetnansky R: Alcohol alters rat adrenomedullary function and stress response. Ann NY Acad Sci 1018: 173-182, 2004
36. Patterson-Buckendahl P, Kvetnansky R, Fukuhara K, Cizza G and Cann C: Regulation of plasma osteocalcin by corticosterone and norepinephrine during restraint stress. Bone 17: 467-472, 1995.

37. Adachi Y, Bradford BU, Gao W, Bojes HK and Thurman RG: Inactivation of Kupffer cells prevents early alcohol-induced liver injury. Hepatology 20: 453-460, 1994.

38. Earnest DL, Abril ER, Jolley CS and Martinez F: Ethanol and diet-induced alterations in Kupffer cell function. Alcohol Alcohol 28: 73-83, 1993.

39. Thakur V, Pritchard MT, McMullen MR and Nagy LE: Adiponectin normalizes LPS-stimulated TNF-alpha production by rat Kupffer cells after chronic ethanol feeding. Am J Physiol Gastrointest Liver Physiol 290: G998-G1007, 2006.

40. Hahn PY, Wang P, Tait SM, Ba ZF, Reich SS and Chaudry IH: Sustained elevation in circulating catecholamine levels during polymicrobial sepsis. Shock 4: 269-273, 1995

41. Kovarik MF, Jones SB and Romano FD: Plasma catecholamines following cecal ligation and puncture in the rat. Circ Shock 22 281-290, 1987.

42. Zhou M, Yang S, Koo DJ, Ornan DA, Chaudry IH and Wang P: The role of Kupffer cell alpha(2)-adrenoceptors in norepinephrine-induced TNF-alpha production. Biochim Biophys Acta 1537: 49-57, 2001

43. Miksa M, Das P, Zhou M, et al: Pivotal role of the alpha(2A)adrenoceptor in producing inflammation and organ injury in a rat model of sepsis. PLoS One 4: e5504, 2009.

44. Yang S, Koo DJ, Zhou M, Chaudry IH and Wang P: Gut-derived norepinephrine plays a critical role in producing hepatocellular dysfunction during early sepsis. Am J Physiol Gastrointest Liver Physiol 279: G1274-G1281, 2000.

45. Zhou M, Hank Simms H and Wang P: Increased gut-derived norepinephrine release in sepsis: up-regulation of intestinal tyrosine hydroxylase. Biochim Biophys Acta 1689: 212-218, 2004.

46. Loegering DJ and Commins LM: Effect of beta-receptor stimulation on Kupffer cell complement receptor clearance function. Circ Shock 25: 325-332, 1988.

47. Koff WC and Dunegan MA: Modulation of macrophagemediated tumoricidal activity by neuropeptides and neurohormones. J Immunol 135: 350-354, 1985.

48. Atkinson JP, Sullivan TJ, Kelly JP and Parker CW: Stimulation by alcohols of cyclic AMP metabolism in human leukocytes. Possible role of cyclic AMP in the anti-inflammatory effects of ethanol. J Clin Invest 60: 284-294, 1977.

49. Libon C, Forestier F, Cotte-Laffitte J, Labarre C and Quero AM: Effect of acute oral administration of alcohol on superoxide anion production from mouse alveolar macrophages. J Leukoc Biol 53: 93-98, 1993

50. Parlesak A, Diedrich JP, Schafer C and Bode C: A low concentration of ethanol reduces the chemiluminescence of human granulocytes and monocytes but not the tumor necrosis factor alpha production by monocytes after endotoxin stimulation. Infect Immun 66: 2809-2813, 1998.

51. Ye L, Wang S, Wang X, et al: Alcohol impairs interferon signaling and enhances full cycle hepatitis C virus JFH-1 infection of human hepatocytes. Drug Alcohol Depend 112: 107-116, 2010.

52. Singal AK and Anand BS: Mechanisms of synergy between alcohol and hepatitis C virus. J Clin Gastroenterol 41: 761-772, 2007.

53. Flierl MA, Rittirsch D, Huber-Lang M, Sarma JV and Ward PA Catecholamines - crafty weapons in the inflammatory arsenal of immune/inflammatory cells or opening pandora's box? Mol Med 14: $195-204,2008$

54. Flierl MA, Rittirsch D, Nadeau BA, et al: Phagocyte-derived catecholamines enhance acute inflammatory injury. Nature 449: 721-725, 2007.

55. Lieber CS: Alcohol, protein nutrition, and liver injury. Curr Concepts Nutr 12: 49-71, 1983.

56. Lieber CS: Biochemical mechanisms of alcohol-induced hepatic injury. Alcohol Alcohol 1: S283-S290, 1991.

57. Setshedi M, Wands JR and Monte SM: Acetaldehyde adducts in alcoholic liver disease. Oxid Med Cell Longev 3: 178-185, 2010.

58. Purohit V, Gao B and Song BJ: Molecular mechanisms of alcoholic fatty liver. Alcohol Clin Exp Res 33: 191-205, 2009.

59. Munford RS, Andersen JM and Dietschy JM: Sites of tissue binding and uptake in vivo of bacterial lipopolysaccharide-high density lipoprotein complexes: studies in the rat and squirrel monkey. J Clin Invest 68: 1503-1513, 1981. 
60. Roth J, McClellan JL, Kluger MJ and Zeisberger E: Attenuation of fever and release of cytokines after repeated injections of lipopolysaccharide in guinea-pigs. J Physiol 477: 177-185, 1994.

61. Wolter J, Liehr H and Grun M: Hepatic clearance of endotoxins: differences in arterial and portal venous infusion. $\mathrm{J}$ Reticuloendothel Soc 23: 145-152, 1978.

62. Wheeler MD: Endotoxin and Kupffer cell activation in alcoholic liver disease. Alcohol Res Health 27: 300-306, 2003.

63. Neuman MG, Shear NH, Bellentani S and Tiribelli C: Role of cytokines in ethanol-induced cytotoxicity in vitro in Hep G2 cells. Gastroenterology 115: 157-166, 1998.

64. Yee SB, Ganey PE and Roth RA: The role of Kupffer cells and TNF-alpha in monocrotaline and bacterial lipopolysaccharideinduced liver injury. Toxicol Sci 71: 124-132, 2003.

65. Takeda K and Akira S: Toll-like receptors in innate immunity. Int Immunol 17: 1-14, 2005.
66. Tracey KJ: Reflex control of immunity. Nat Rev Immunol 9: 418-428, 2009.

67. Tracey KJ: The inflammatory reflex. Nature 420: 853-859, 2002.

68. Akerman P, Cote P, Yang SQ, et al: Antibodies to tumor necrosis factor-alpha inhibit liver regeneration after partial hepatectomy. Am J Physiol 263: G579-G585, 1992.

69. Gressner AM and Chunfang G: A cascade-mechanism of fat storing cell activation forms the basis of the fibrogenic reaction of the liver. Verh Dtsch Ges Pathol 79: 1-14, 1995.

70. Gressner OA, Rizk MS, Kovalenko E, Weiskirchen R and Gressner AM: Changing the pathogenetic roadmap of liver fibrosis? Where did it start; where will it go? J Gastroenterol Hepatol 23: 1024-1035, 2008. 